\title{
Shear Model of Metal Melt Flowing on Vibration Wall and Effect of Shear Stress on Solidification Microstructure
}

\author{
Ren-Guo Guan ${ }^{1,2} \cdot$ Xiang Wang $^{2} \cdot$ Ying-Qiu Shang ${ }^{2} \cdot$ Di Tie $^{2} \cdot$ Run-Ze Chao ${ }^{3}$
}

Received: 4 July 2017 / Revised: 8 September 2017/Published online: 18 December 2017

(C) The Chinese Society for Metals and Springer-Verlag GmbH Germany, part of Springer Nature 2017

\begin{abstract}
In this work, the shear model of metal melt flowing on vibration surface is established, and coupling effects of vibration and shear on the distribution of shear stress in melt and melt solidification microstructure are analyzed. Calculation results show that the transition of melt from laminar flow to turbulent flow occurs earlier with increasing vibration frequency and vibration amplitude. In the laminar flow melt, shear stress in melt decreases with increasing vertical length, but it decreases firstly and then stabilizes with increasing flow length. In the turbulent flow melt, shear stress decreases firstly and then stabilizes with increasing vertical length, but it increases with increasing flow length. With the increase in vibration frequency and amplitude, shear stress along flow direction in laminar flow melt increases, while shear stresses along both flow direction and vertical direction in turbulent flow melt increase. Shear stress in melt decreases with increasing length along vertical direction. With the increase in flow length, shear stress decreases firstly and then stabilizes in laminar flow melt, while it increases in turbulent flow melt. With the increase in vibration frequency and amplitude, shear stress increases in laminar flow melt, while it stabilizes in turbulent flow melt. Based on theoretical calculation, the maximum shear stress in melt during vibration shear flow is always much lower than the yield strength of $\alpha$-Al grain, so the shear stress induced by vibration shear flow cannot break columnar crystal, which agrees with the experiment result. So, the model can explain the shear constitutive relation of melt flow on vibration surface relatively well.
\end{abstract}

Keywords Solidification · Flow near surface $\cdot$ Shear · Vibration · Columnar crystal

\section{Introduction}

In order to improve the microstructure and mechanical properties of casting, vibration is widely applied to the process of melt treatment in order to refine grain size. There are a number of studies about the effect of vibration on microstructure $[1,2]$. On the one hand, vibration can strengthen energy fluctuation and increase nucleation rate and thus lead to grain refinement. The effect of ultrasonic

Available online at http://link.springer.com/journal/40195

Xiang Wang

15840319082@126.com

1 School of Materials Science and Engineering, Northwestern Polytechnical University, Xi' an 710072, China

2 School of Materials Science and Engineering, Northeastern University, Shenyang 110819, China

3 Luoyang Ship Material Research Institute, Luoyang 471000, China vibration on solidification microstructure of A356 alloy was researched by Jian et al. [3], and it was found that the grain was obviously refined after ultrasonic vibration was added, and the reason of grain refinement was the heterogeneous nucleation induced by the cavitation effect of ultrasonic vibration. On the other hand, the shear stress induced by vibration can break the grain in melt. According to the research result of Flemings [4], shear stress in flowing melt could break the second dendrite arm. In addition, Abu-Dheir et al. [5] have researched the effect of mechanical vibration with the frequency of $100 \mathrm{~Hz}$ on the solidification microstructure of eutectic Al-Si alloy, and they found that dendrite was broken successfully. What is more, in the research of Guo et al. [6], mechanical vibration could not only strengthen energy fluctuation, structure fluctuation, and component fluctuation in melt, but also break the initial nuclei, so the microstructure was obviously refined. However, some researchers hold the opinion that the shear stress could not break the grain. Pilling and Hellawell [7] built a stress model of dendrite arm in 
flowing melt, and it was found that the shear stress acting on dendrite arm was far lower than the critical shear stress which could break the dendrite arm. Lu et al. [8] have analyzed the shear stress acting on dendrite arm in melt under the function of ultrasonic vibration, and the result showed that shear stress induced by ultrasonic vibration could only lead to the plastic deformation of dendrite arm rather than break it. In conclusion, vibration has a significant effect on the shear stress in flow melt, but the shear stress induced by the coupling effects of flow and vibration is still lacking in systematic study. Additionally, the shear model of melt flowing on a slope with vibration is not established, and the present study does not quantitatively calculate the shear stress field under the coupling effect of vibration and flow. How does the vibration and flow synergistically affect the shear stress in the melt? Whether vibration or flow is the dominant factor? These questions are not clear, and all of them can only be answered by quantitative models.

Vibration cooling slope [9-11] is an effective, low-cost, and short processing method of melt treatment. When overheated melt is cast onto a vibration cooling slope, a number of heterogeneous nucleation are induced on the surface of slope due to the strong cooling of slope. Under the function of flow and vibration, heterogeneous nucleation is swept into the mold, and finally solidification microstructure composed of fine spherical grain is formed [12]. Shear stress induced in melt flowing on a vibration slope can bend primary grain, and the shear stress is a representative shear stress induced by the coupling effects of flow and vibration. In this work, a shear model of melt flowing on vibration wall is established to quantitatively calculate the shear stress field and give answers to the above questions, and the effect of shear stress on solidification microstructure is analyzed based on previous researches [13-16]. Moreover, a verification experiment is carried out. So, this work can provide guidelines to correlative research of melt.

\section{Shear Model of Melt Flowing on Vibration Wall}

When melt flows on a slope under the effect of gravity, there is a velocity gradient in the melt due to the friction between the slope surface and melt, and shear stress is formed. When vibration is added to the slope, the velocity gradient in the melt will be changed, and thus, the shear stress will also be changed. In this work, vibration direction of slope is parallel to the flowing direction of melt. Figure 1a shows the diagram of melt flowing on a vibration slope, and Fig. 1b shows the geometric model of melt flowing on a vibration slope. $H$ is casting height, $\theta$ is slope angle, $f$ is vibration frequency, and $A$ is vibration amplitude. The following assumptions are made in order to describe the physical process of melt flowing on vibration slope: (1) the vibration of slope is sinusoidal; (2) the vibrations of slope and melt are synchronous; (3) the viscosity of melt is constant. The physical process can be described as follows:

$s=A \sin 2 \pi f t$,

$V=\frac{\mathrm{d} s}{\mathrm{~d} t}=2 \pi f A \cos 2 \pi f t$,

$a=\frac{\mathrm{d}^{2} s}{\mathrm{~d} t^{2}}=-4 \pi^{2} f^{2} A \sin 2 \pi f t$

where $s$ is vibration displacement, $t$ is vibration time, $V$ is vibration velocity, and $a$ is vibration acceleration.

Reynolds number of melt flowing on slope can be described as $\operatorname{Re}_{x}=\frac{u_{\infty} x}{v}$, in which $\operatorname{Re}_{x}$ is flow Reynolds number, $u_{\infty}=\left(2 g H \sin ^{2} \theta+2 g x \sin \theta\right)^{1 / 2}$ is flow velocity, $v$ is kinematic viscosity of the melt, $x$ is flow length, and $g$ is gravitational acceleration [17]. Flow condition of melt on a slope is changed after vibration is added to the slope [18], and it is determined by the coupling effects of flow parameters and vibration parameters. According to relative research of melt flowing under the function of vibration, effect of vibration on melt flowing can be regarded as the effect of vibration on the Reynolds number of flowing melt. Take the effects of vibration frequency and vibration amplitude into consideration together, vibration Reynolds number $R e_{\mathrm{v}}$ is introduced [19], and $\operatorname{Re}_{\mathrm{V}}=\frac{2 \pi f A x}{v}$. So, Reynolds number of melt flowing under coupling effects of shear and vibration is as follows:

$\operatorname{Re}=\operatorname{Re}_{x}+\operatorname{Re}_{\mathrm{V}}=\frac{x}{v}\left(u_{\infty}+2 \pi f A\right)$,

where $\mathrm{Re}$ is Reynolds number and $\mathrm{Re}_{\mathrm{v}}$ is vibration Reynolds number. The common A356 alloy is used as an example for theoretical calculation and verification experiment, and the composition of A356 is shown in Table 1. Set the critical Reynolds number is $5 \times 10^{5}$, kinematic viscosity of melt $(v)$ is $4.82 \times 10^{-7} \mathrm{~m}^{2} / \mathrm{s}$, slope angle $(\theta)$ is $45^{\circ}$, and casting height $(H)$ is $0.1 \mathrm{~m}$. When Reynolds number is lower than the critical Reynolds number, the melt is laminar; when Reynolds number is higher than the critical Reynolds number, the melt is turbulent. Based on Eq. (4), the distributions of Reynolds numbers of melt under different vibration parameters are shown in Fig. 2. Figure $2 \mathrm{a}$ shows the effect of vibration frequency on the distribution of Reynolds number when vibration amplitude is $1 \mathrm{~mm}$. It can be seen that the transition of melt from laminar flow to turbulent flow also exists in melt when the slope vibrates, and the transition of flow type appears earlier with increasing vibration frequency. When vibration 
(a)

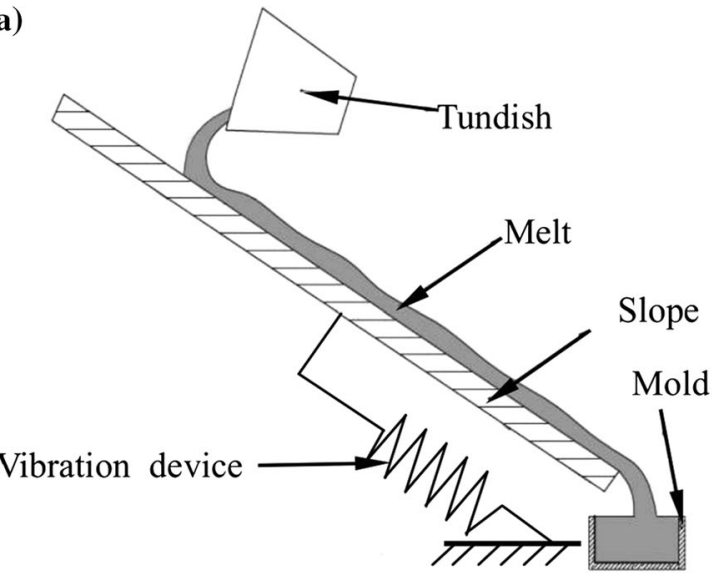

Fig. 1 Diagram a, geometric $\mathbf{b}$ models of melt flow on vibration slope

Table 1 Chemical composition of A356 alloy

\begin{tabular}{lllll}
\hline $\mathrm{Si}$ & $\mathrm{Mg}$ & $\mathrm{Fe}$ & $\mathrm{Ti}$ & $\mathrm{Al}$ \\
\hline $6.5-7.5$ & $0.25-0.45$ & 0.2 & 0.2 & $\mathrm{Bal}$.
\end{tabular}

frequency is 30,70 , and $100 \mathrm{~Hz}$, the transitions of flow type correspondingly appear at $0.130,0.118$, and $0.109 \mathrm{~m}$, respectively. Figure $2 b$ shows the effect of vibration amplitude on the distribution of Reynolds number when vibration frequency is $70 \mathrm{~Hz}$. It can be found that the transition of melt from laminar flow to turbulent flow appears earlier with increasing vibration amplitude. When vibration amplitudes are 1,2, and $3 \mathrm{~mm}$, the transitions of flow type correspondingly appear at $0.118,0.100$, and $0.086 \mathrm{~m}$, respectively. The transition of melt from laminar flow to turbulent flow appears at $0.141 \mathrm{~m}$ when the slope does not vibrate [14]. So, vibration can lead to the transition of melt flow type which appears in advance, compared to transition of melt flow type on static slope. The reason is

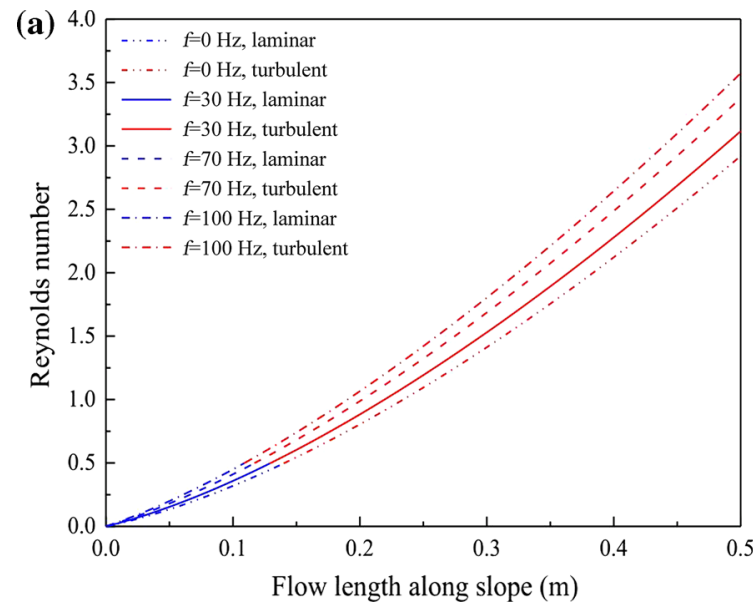

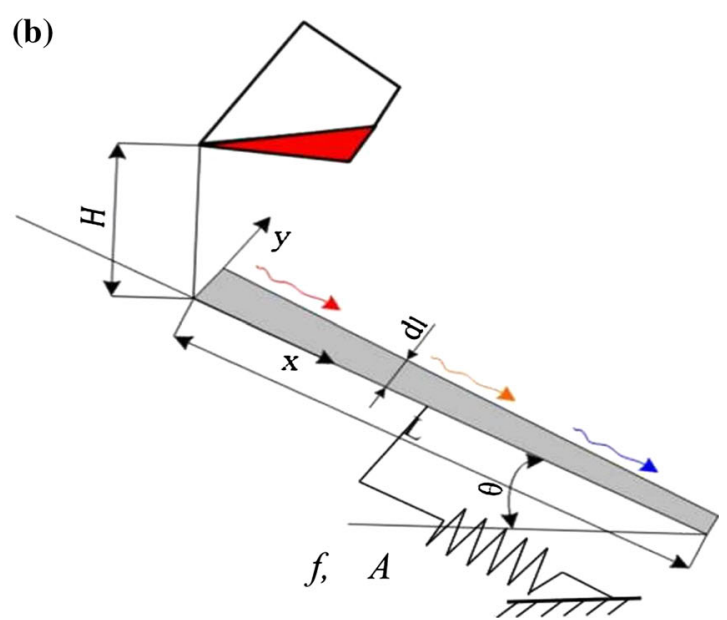

that vibration can induce disturbance in melt, and the disturbance can promote the transition of melt flow.

Previous research result [13] shows that shear stress in laminar flow melt on slope without vibration can be described as:

$\tau_{1}=\mu u_{\infty}\left(0.3 \frac{\operatorname{Re}^{0.5}}{x}-0.012 y^{2} \frac{\operatorname{Re}^{1.5}}{x^{3}}\right)$,

where $\mu$ is the viscosity of melt and $y$ is the length vertical to slope. In turbulent flow melt, the shear stress can be described as:

$\tau_{\mathrm{t}}=\frac{\mu}{7}\left(2 g H \sin ^{2} \theta+2 g x \sin \theta\right)^{1 / 2}\left(\frac{1}{0.376 x y^{6}}\right)^{1 / 7} \operatorname{Re}^{1 / 35}$.

So shear stress in laminar flow melt on vibration slope is as follows:

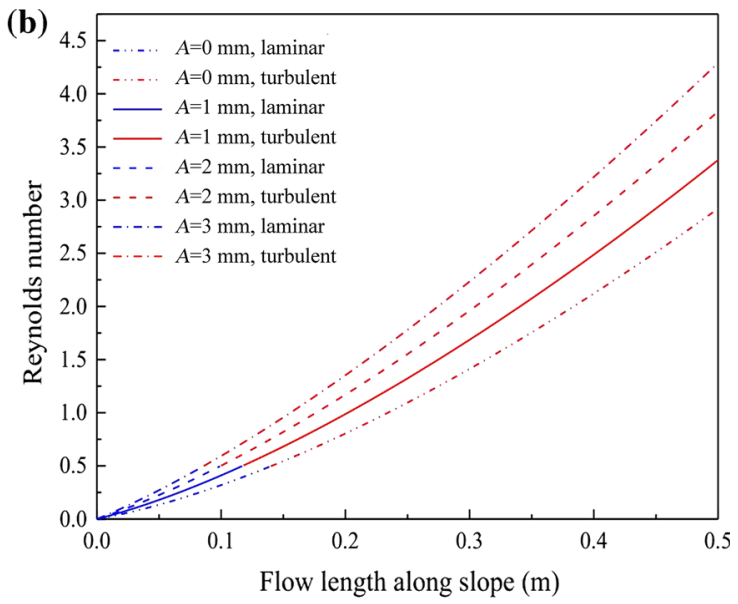

Fig. 2 Distributions of Reynolds number of A356 alloy melt along flow direction at different frequencies a, amplitudes b 
$\tau_{1}=\mu u_{\infty}\left[0.3\left(\frac{u_{\infty}+2 \pi f A}{v x}\right)^{0.5}-0.012 y^{2}\left(\frac{u_{\infty}+2 \pi f A}{v x}\right)^{1.5}\right]$

when $x$ is $0.04 \mathrm{~m}, H$ is $0.1 \mathrm{~m}$, and $\theta$ is $45^{\circ}$, the distributions of shear stress in laminar flow A356 alloy melt along vertical direction of slope under different vibration parameters are shown in Fig. 3. Figure 3a shows the effect of vibration frequency when vibration amplitude is constant $(1 \mathrm{~mm})$, and Fig. $3 \mathrm{~b}$ shows the effect of vibration amplitude when vibration frequency is constant $(70 \mathrm{~Hz})$. In Fig. 3, the intercept of vertical ordinate is the maximum shear stress in melt, while the intercept of horizontal ordinate is the thickness of velocity boundary layer. The shear stress is 0 at the out of velocity boundary layer. It can be found that shear stress in melt decreases with increasing length vertical to the slope whether the slope vibrates or not [14]. After vibration is added to the slope, the maximum shear stress increases with the increase in vibration frequency and vibration amplitude. However, the thickness of velocity boundary layer decreases when the slope vibrates, and the shear stress increases faster with the increase in vibration frequency and vibration amplitude in velocity boundary layer.

When $H$ is $0.1 \mathrm{~m}$ and $\theta$ is $45^{\circ}$, the distributions of shear stress in laminar flow A356 alloy melt along flow direction under different vibration parameters are shown in Fig. 4. Figure $4 \mathrm{a}$ shows the effect of vibration frequency when vibration amplitude remains constant $(1 \mathrm{~mm})$, and Fig. $4 \mathrm{~b}$ shows the effect of vibration amplitude when vibration frequency remains constant $(70 \mathrm{~Hz})$. Figure 4 shows that shear stress in melt rapidly decreases and then stabilizes with increasing flow length, but it only slightly increases when the slope vibrates. The reason is that at the moment when melt is casted onto the surface of slope, velocity boundary layer thickness in the melt is almost 0 and the velocity gradient near the surface is very high, so the shear stress closed to slope surface is large [14]. With the increase in flow length, velocity boundary layer thickness in melt increases, and velocity gradient decreases, so shear stress decreases and tends to be stabilized.

Similarly, shear stress in turbulent flow melt on vibration slope is as follows:

$$
\begin{aligned}
\tau_{\mathrm{t}}= & \frac{\mu}{7}\left(2 g H \sin ^{2} \theta+2 g x \sin \theta\right)^{1 / 2}\left(\frac{1}{0.376 x y^{6}}\right)^{1 / 7} \\
& \left(\frac{x\left(2 g H \sin ^{2} \theta+2 g x \sin \theta\right)^{0.5}+2 \pi f A x}{v}\right)^{1 / 35},
\end{aligned}
$$

when $x$ is $0.04 \mathrm{~m}, H$ is $0.1 \mathrm{~m}$, and $\theta$ is $45^{\circ}$, the distributions of shear stresses in turbulent flow A356 alloy melt along vertical direction of slope under different vibration parameters are shown in Fig. 5. Figure 5a shows the effect of vibration frequency when vibration amplitude is $1 \mathrm{~mm}$, and Fig. 5b shows the effect of vibration amplitude when vibration frequency is $70 \mathrm{~Hz}$. Figure 5 shows that shear stress decreases firstly and then stabilizes with increasing vertical length. Compared to melt flowing on slope without vibration, the shear stress in melt flowing on vibration slope increases, and it increases with increasing vibration frequency and vibration amplitude.

When $H$ is $0.1 \mathrm{~m}$, and $\theta$ is $45^{\circ}$, the distributions of shear stresses in turbulent flow A356 alloy melt along flow direction under different vibration parameters are shown in Fig. 6. The effect of vibration frequency is shown in Fig. 6a when vibration amplitude is $1 \mathrm{~mm}$, and the effect of vibration amplitude is shown in Fig. 6b when vibration frequency is $70 \mathrm{~Hz}$. It can be found that shear stress in melt increases with the increase in flow length [14], and vibration frequency as well as vibration amplitude strengthens the shear stress.
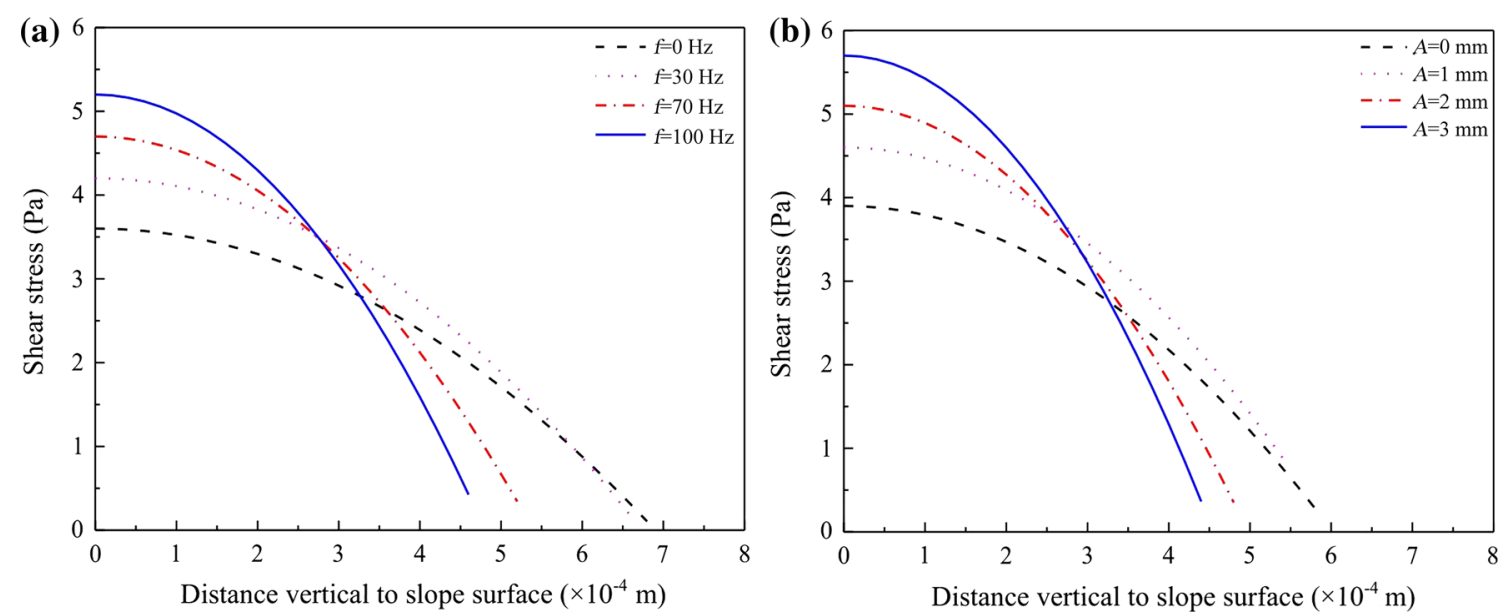

Fig. 3 Distributions of shear stresses along vertical direction of slope at different vibration frequencies $\mathbf{a}$, amplitudes $\mathbf{b}$ in laminar flow melt 

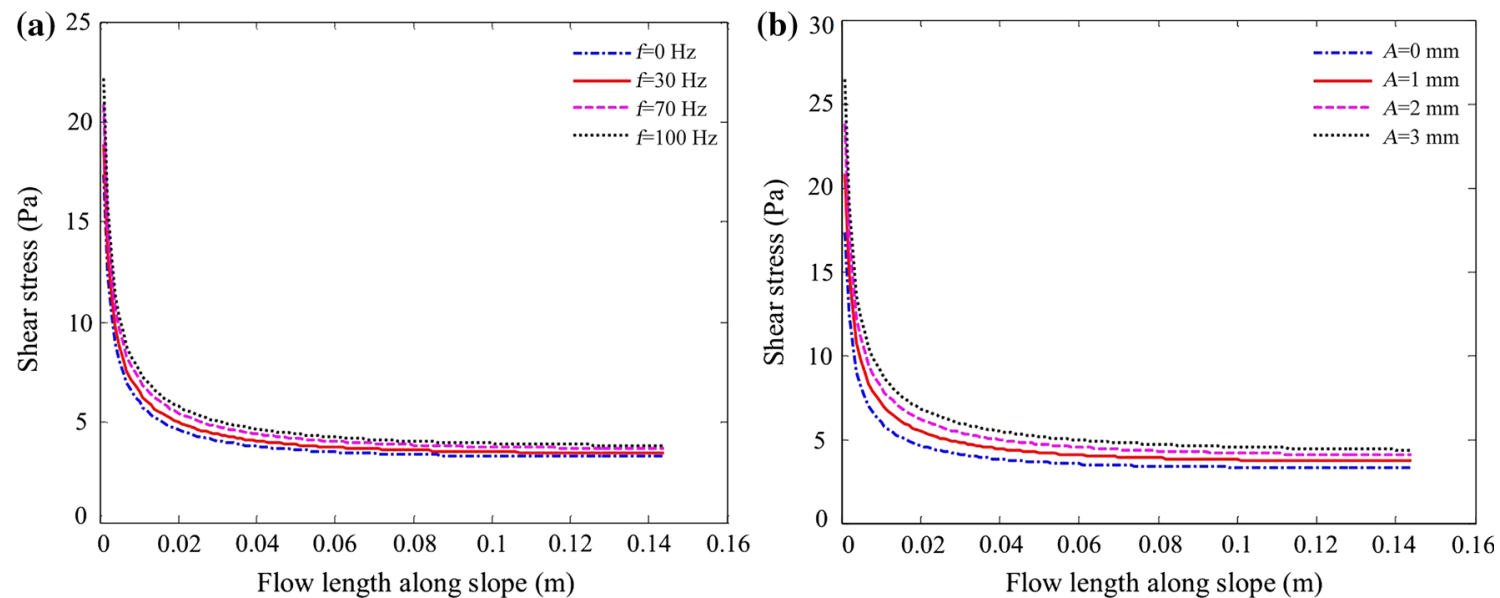

Fig. 4 Distributions of shear stresses along parallel direction of slope at different vibration frequencies $\mathbf{a}$, amplitudes $\mathbf{b}$ in laminar flow melt
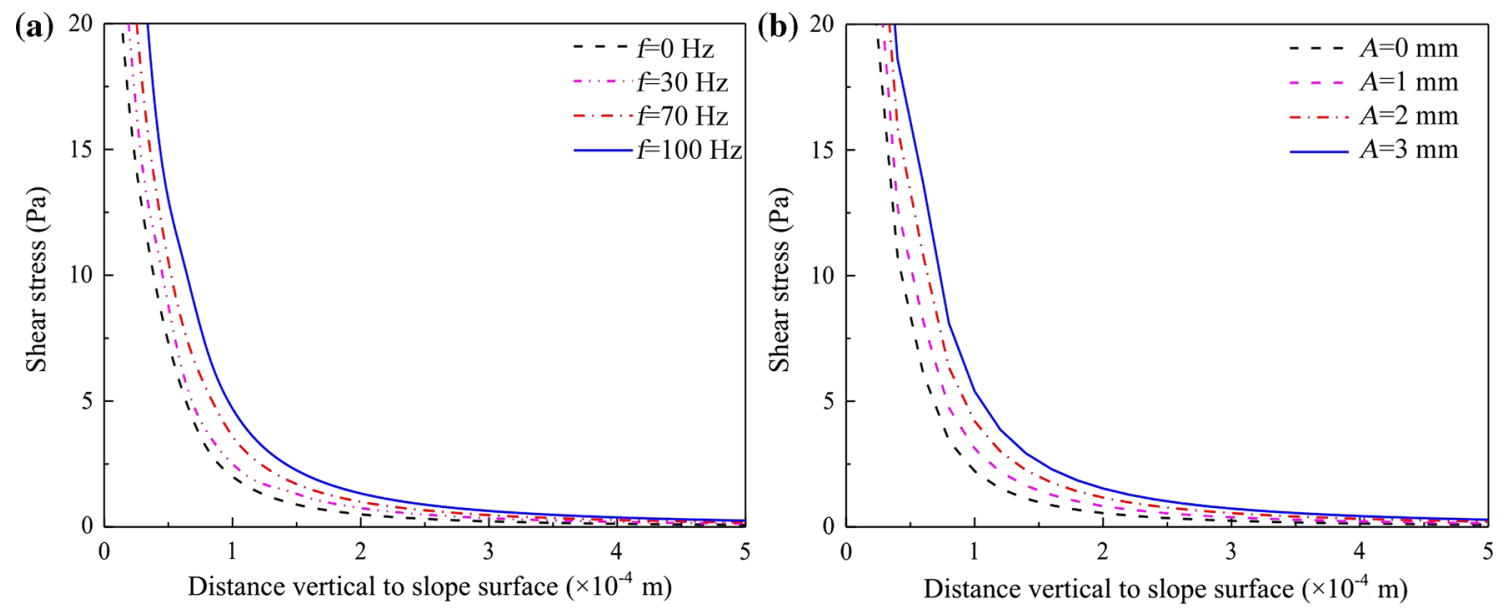

Fig. 5 Distributions of shear stresses along vertical direction of slope at different vibration frequencies $\mathbf{a}$, amplitudes $\mathbf{b}$ in turbulent flow melt
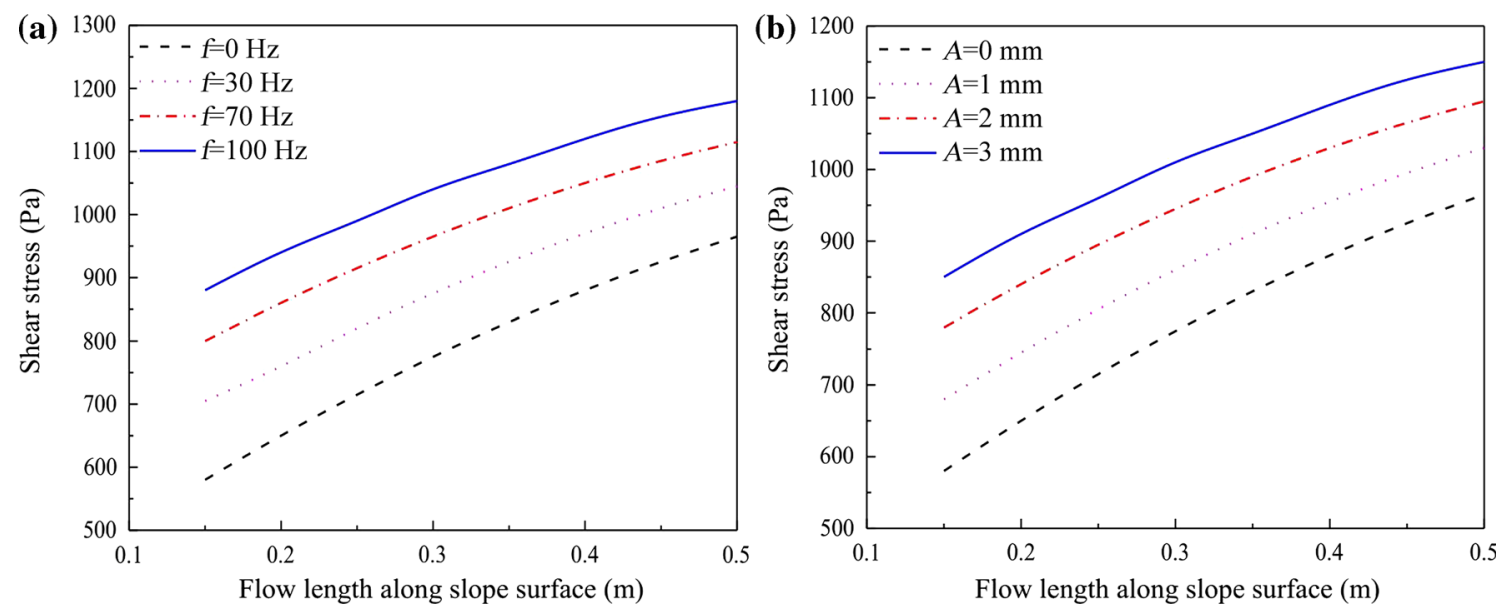

Fig. 6 Distributions of shear stresses along flow direction at different vibration frequencies a, amplitudes $\mathbf{b}$ in turbulent flow melt 


\section{Effect of Shear Stress on Solidification Microstructure}

Columnar crystal is subjected to vibration force after vibration is applied to slope, and the vibration force $F_{\mathrm{v}}$ is shown as follows according to Newton second law:

$F_{\mathrm{v}}=m a=\rho A \pi^{3} D^{2} f^{2}\left(L_{0}-y\right) \sin 2 \pi f t$,

where $F_{\mathrm{v}}$ is vibration force, $m$ is the mass of columnar crystal, $\rho$ is the density of columnar crystal, $L_{0}$ is the length of columnar crystal, and $D$ is the diameter of columnar crystal arm. Stress induced by vibration acting at the root of columnar crystal $\sigma_{\mathrm{lv}}$ is shown as follows:

$\sigma_{\mathrm{lv}}=4 \rho A \pi^{2} f^{2}\left(L_{0}-y\right) \sin 2 \pi f t$.

The bending stress acting at the root of columnar crystal on vibration slope can be divided into two parts: one bending stress is induced by melt flow, while another bending stress is induced by vibration. However, the two bending stresses are parallel to each other, and so they can be superimposed and $\sigma_{1}=\sigma_{\mathrm{ls}}+\sigma_{\mathrm{lv}}$. ( $\sigma_{1}$ is bending stress acting at the root of columnar crystal induced by vibration and flow, and $\sigma_{\mathrm{ls}}$ is the bending stress induced by melt flow.) Columnar crystal can be treated as a cantilever beam, and the shear stress acting on columnar crystal in laminar flow melt on slope without vibration is shown as [14]:

$\sigma_{\mathrm{ls}}=\frac{64 \mu u_{\infty}}{\pi D^{2}}\left[\frac{3 \operatorname{Re}^{0.5}}{20 x}\left(L_{0}^{2}-y^{2}\right)-\frac{3 \operatorname{Re}^{1.5}}{1000 x^{3}}\left(L_{0}^{4}-y^{4}\right)\right]$.

So, the maximum shear stress acting on columnar crystal in laminar flow melt on vibration slope is shown as follows when $\sin 2 \pi f t=1$ :

$$
\begin{aligned}
\sigma_{\operatorname{lmax}}= & 4 \rho A \pi^{2} f^{2}\left(L_{0}-y\right) \\
& +\frac{64 \mu u_{\infty}}{\pi D^{2}}\left[\frac{3 \operatorname{Re}^{0.5}}{20 x}\left(L_{0}^{2}-y^{2}\right)-\frac{3 \operatorname{Re}^{1.5}}{1000 x^{3}}\left(L_{0}^{4}-y^{4}\right)\right],
\end{aligned}
$$

when $x$ is $0.04 \mathrm{~m}, H$ is $0.1 \mathrm{~m}$, and $\theta$ is $45^{\circ}$, the distributions of bending stresses acting on columnar crystal in laminar flow A356 alloy melt along vertical direction of slope under different vibration parameters are shown in Fig. 7. Figure $7 \mathrm{a}$ shows the effect of vibration frequency when vibration amplitude is constant $(1 \mathrm{~mm})$, and Fig. $7 \mathrm{~b}$ shows the effect of vibration amplitude when vibration frequency remains constant $(70 \mathrm{~Hz})$. Figure 7 shows that bending stress decreases with increasing vertical length, and it increases in melt on vibration slope. With the increase in vibration frequency and vibration amplitude, the shear stress increases. The bending stress acting at the root of columnar crystal is the maximum, and the maximum shear stress can increase from 350 to $500 \mathrm{~Pa}$ when the vibration frequency is $70 \mathrm{~Hz}$ and vibration amplitude is $3 \mathrm{~mm}$.

Similarly, the maximum shear stress acting on columnar crystal in turbulent flow melt on vibration slope is as follows:

$$
\begin{aligned}
\sigma_{\text {tman }}= & 4 \rho A \pi^{2} f^{2}\left(L_{0}-y\right)+\frac{9.2 \mu L_{0}^{8 / 7}}{\pi D^{2}}\left(2 g H \sin ^{2} \theta+2 g x \sin \theta\right)^{1 / 2} \\
& \times\left[\frac{\left(2 g H \sin ^{2} \theta+2 g x \sin \theta\right)^{0.5}+2 \pi f A}{v x^{4}}\right]^{1 / 35}
\end{aligned}
$$

when $x$ is $0.04 \mathrm{~m}, H$ is $0.1 \mathrm{~m}$, and $\theta$ is $45^{\circ}$, the distributions of bending stresses acting on columnar crystal in turbulent flow A356 alloy melt along vertical direction of slope under different vibration parameters are shown in Fig. 8. The effect of vibration frequency is shown in Fig. 8a when vibration amplitude is $1 \mathrm{~mm}$, and the effect of vibration amplitude is shown in Fig. $8 \mathrm{~b}$ when vibration frequency is $70 \mathrm{~Hz}$. Figure 8 shows that bending stress decreases with increasing vertical length, and it slightly increases with the increase in vibration frequency and vibration amplitude. The maximum shear stress which is acted at the root of columnar crystal only increases from 2000 to $2200 \mathrm{~Pa}$.

When $H$ is $0.1 \mathrm{~m}$ and $\theta$ is $45^{\circ}$, the distributions of bending stresses acting on columnar crystal in A356 alloy melt along flow direction under different vibration parameters are shown in Fig. 9. Figure 9a shows the effect of vibration frequency when vibration amplitude is $1 \mathrm{~mm}$, and Fig. $9 \mathrm{~b}$ shows the effect of vibration amplitude when vibration frequency is $70 \mathrm{~Hz}$. It can be found that the bending stress decreases rapidly, and then, it stabilizes with increasing flow length in laminar flow melt, while it increases with the increase in flow length in turbulent flow melt. The bending stress increases with increasing vibration frequency and vibration amplitude in laminar flow melt, but vibration cannot obviously affect the bending stress in turbulent flow melt. Bending stress acting at the root of columnar crystal is between 1000 and $3000 \mathrm{~Pa}$, which is far lower than the yield strength of $\alpha$-Al crystal $50 \mathrm{kPa}[20,21]$, so the bending stress in melt on vibration slope also cannot break the columnar crystal according to the calculation result.

Figure 10 shows the quenched microstructure of A356 alloy melt adhered on slope with different vibration parameters under a relative low pouring temperature, and the position of the sample is at the end of the slope. When the slope does not vibrate, the quenched microstructure is shown in Fig. 10a, b shows the quenched microstructure when vibration frequency is $100 \mathrm{~Hz}$ and vibration amplitude is $3 \mathrm{~mm}$. It can be seen that the columnar crystals in melt at the exit of slope are bended whether the slope vibrates or not, and the bending degree of columnar crystal 

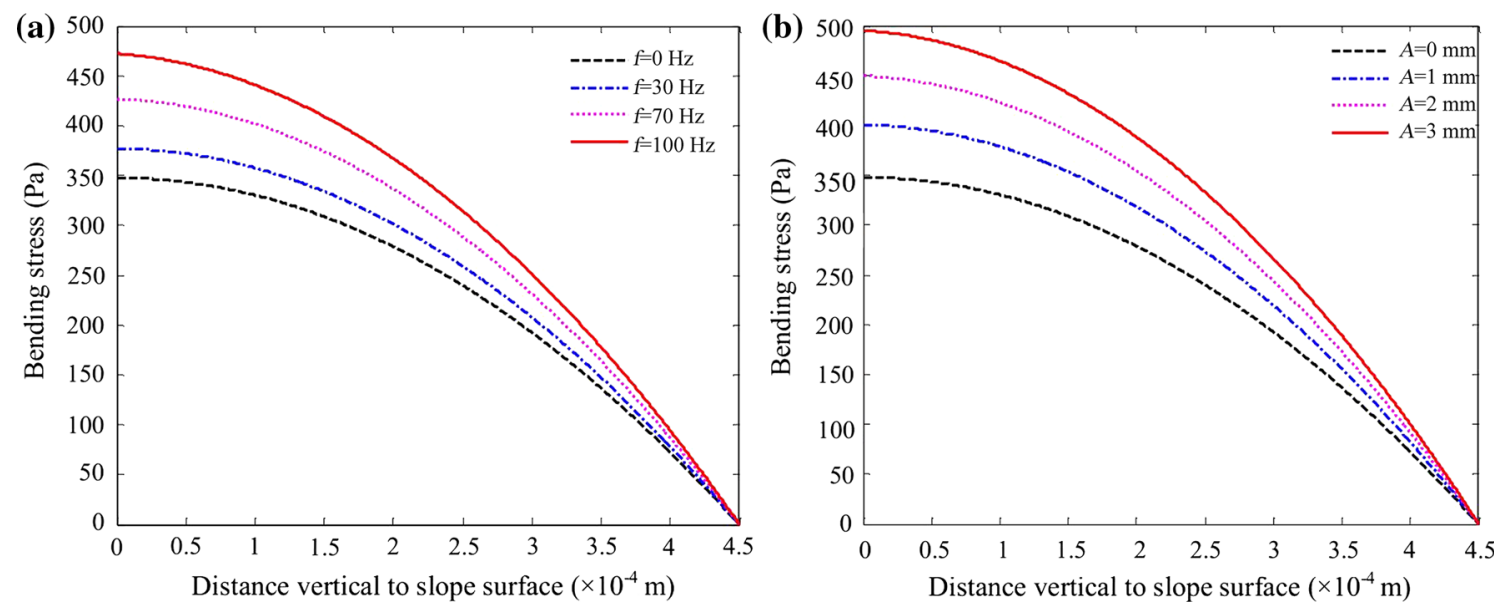

Fig. 7 Distributions of bending stresses along vertical direction of slope at different vibration frequencies $\mathbf{a}$, amplitudes $\mathbf{b}$ in laminar flow melt
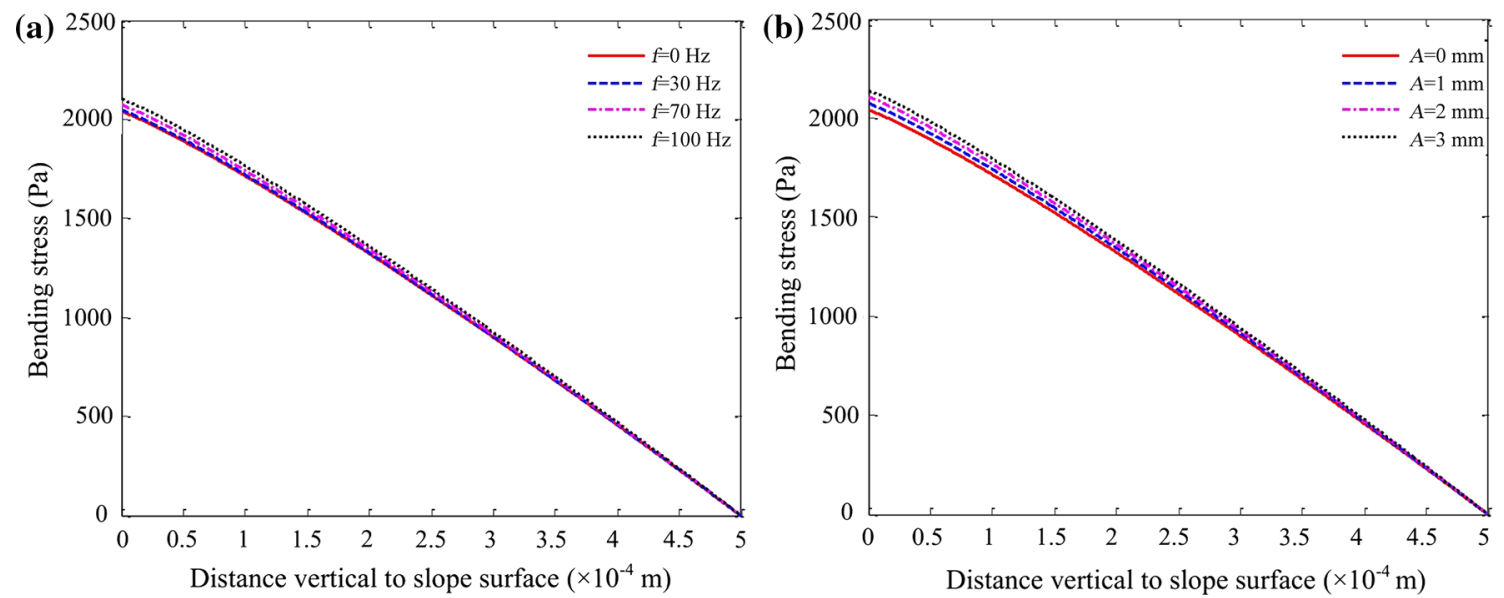

Fig. 8 Distributions of bending stresses along vertical direction of slope at different vibration frequencies $\mathbf{a}$, amplitudes $\mathbf{b}$ in turbulent flow melt
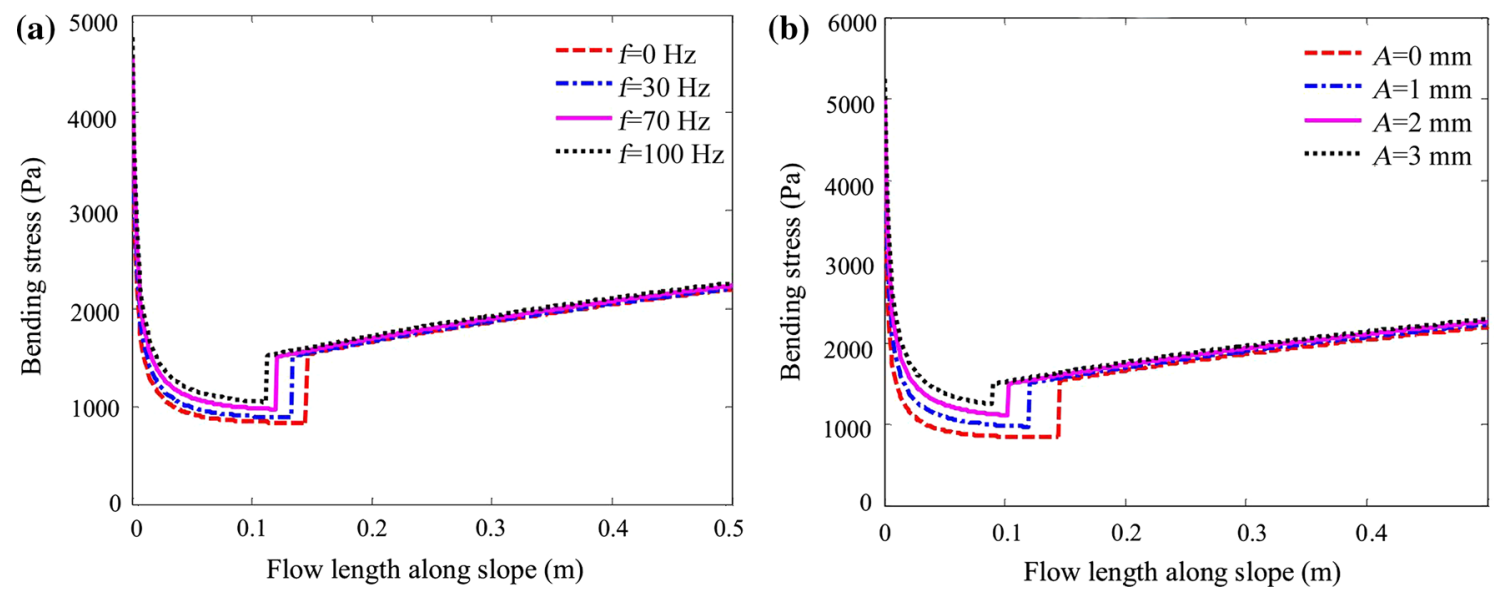

Fig. 9 Distributions of bending stresses along flow direction at different vibration frequencies a, amplitudes $\mathbf{b}$

on slope with vibration is much more obvious than that on slope without vibration. The experiment result verifies that shear stress in melt cannot break the columnar crystal, but the shear stress can bend the columnar crystal, and the shear stress can be improved by vibration. What is more, the grain size in Fig. 10b is slightly larger than that in Fig. 10a. The reason is that nuclei are easier to dissociate on the vibration slope, and the nuclei density on the surface 

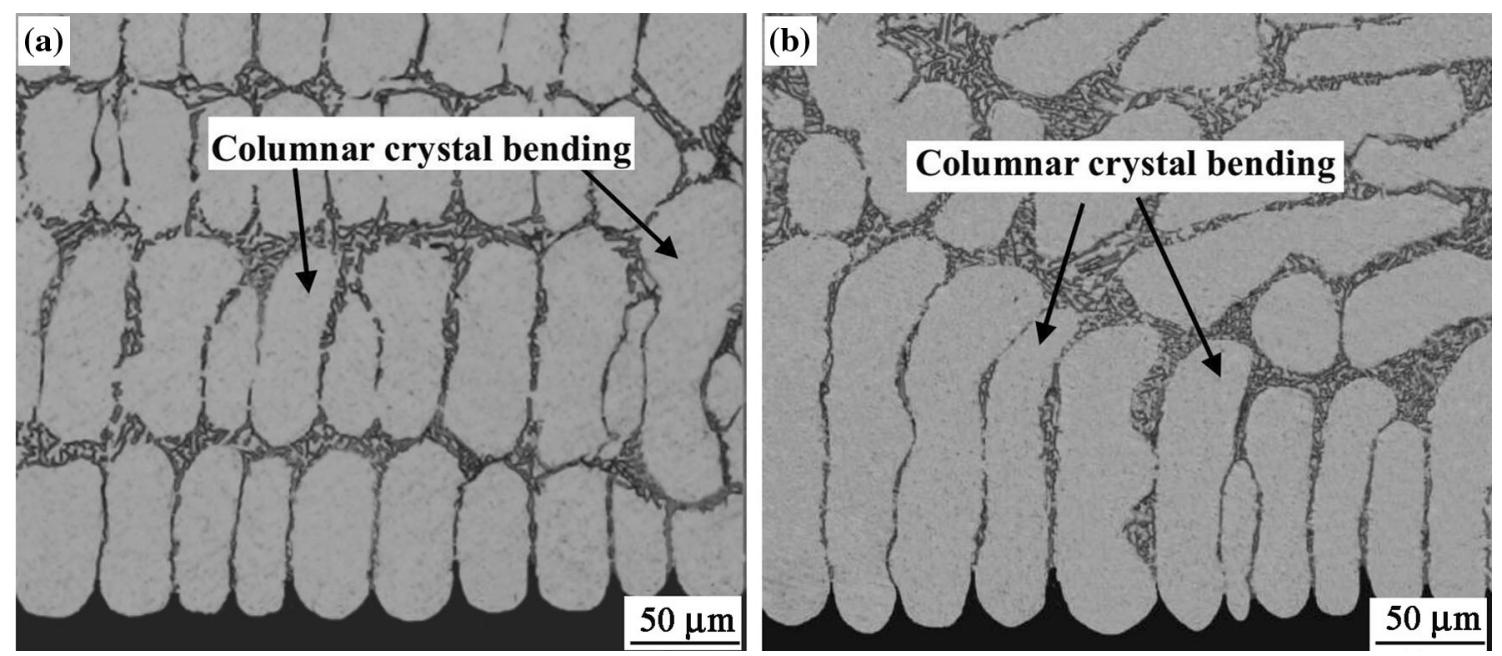

Fig. 10 Quenched microstructures of A356 alloy melt at the exit of slope with different vibration parameters: a no vibration, b vibration frequency is $100 \mathrm{~Hz}$ and vibration amplitude is $3 \mathrm{~mm}$

of slope without vibration is higher than that on the surface of slope with vibration. The growth of high density nuclei is limited by the surrounding nuclei, so the grain size is smaller in the quench sample on slope without vibration. But, this does not indicate that the solidification microstructure of the melt treated by slope without vibration is finer than that treated by slope with vibration. So, the experiment results agree with the above theoretical calculation. However, in the real process of melt treatment on slope, surface tension between crystal and melt, latent heat of solidification, defects in crystal, and other effects should be taken into consideration to examine the bend and break of columnar crystal in melt on vibration slope.

\section{Conclusions}

In this work, the shear model of melt flowing on vibration surface was established, and the effects of vibration and shear on melt solidification microstructure were analyzed. The conclusions are as follows:

1. With the increase in vibration frequency and amplitude, the transition of melt from laminar flow to turbulent flow occurs earlier. In the laminar flow melt, shear stress in melt decreases with the increase in length along vertical direction, and it decreases firstly and then stabilizes with increasing flow length. However, in the turbulent flow melt, the shear stress decreases with increasing length along flow direction, and it decreases firstly and then stabilizes with increasing vertical length. With the increase in vibration frequency and amplitude, shear stress in laminar melt increases along flow direction, while the shear stresses in turbulent flow melt increase along both flow direction and vertical direction.

2. Shear stress acting on columnar crystal in melt decreases with the increase in length along vertical direction. With the increase in flow length, shear stress decreases firstly and then stabilizes in laminar flow melt, while the shear stress increases in turbulent flow melt. With the increase in vibration frequency and amplitude, shear stress increases in laminar flow melt, while shear stress in turbulent flow melt stabilizes.

3. The maximum shear stress in melt during vibration shear flow is much lower than the yield strength of $\alpha$ Al grain, so the shear stress induced by vibration shear flow cannot break columnar crystal, which agrees with the experiment results. So, the model can relatively well explain the shear constitutive relations of the metal melt flowing on vibration surface.

Acknowledgements This work was supported financially by the National Natural Science Foundation of China (Nos. 51474063, 51674077) and the Fundamental Research Funds for the Central Universities (No. N150204016).

\section{References}

[1] R.G. Guan, D. Tie, Acta Metall. Sin. (Engl. Lett.) 30, 409 (2017)

[2] S.L. Lü, S.S. Wu, C. Lin, P. An, Acta Metall. Sin. (Engl. Lett.) 27, 862 (2014)

[3] X. Jian, H. Xu, T.T. Meek, Q. Han, Mater. Lett. 59, 190 (2005)

[4] M.C. Fleming, Metall. Trans. A 22, 957 (1991)

[5] N. Abu-Dheir, M. Khraisheh, K. Saito, A. Male, Mater. Sci. Eng. A 393, 109 (2005)

[6] H.M. Guo, X.J. Yang, X.Q. Luo, S.X. Cheng, M. Wang, Chin. J. Nonferrous Met. 19, 2106 (2009)

[7] J. Pilling, A. Hellawell, Mater. Trans. A 27, 229 (1996) 
[8] S.L. Lu, S.S. Wu, C. Lin, Z.Q. Hu, P. An, Mater. Sci. Eng. A 528, 8635 (2011)

[9] R.G. Guan, Z.Y. Zhao, H. Zhang, C. Lian, C.S. Lee, C.M. Liu, J. Mater. Process. Technol. 212, 1430 (2012)

[10] N.K. Kund, Trans. Nonferrous Met. Soc. 24, 3465 (2014)

[11] H. Khosravi, R.E. Farsani, M.A. Paykani, Trans. Nonferrous Met. Soc. 24, 961 (2014)

[12] R.G. Guan, Z.Y. Zhao, R.Z. Chao, Z.X. Feng, C.M. Liu, Trans. Nonferrous Met. Soc. 22, 2871 (2012)

[13] R.G. Guan, Z.Y. Zhao, H.Q. Huang, C. Lian, R.Z. Chao, C.M. Liu, Acta Phys. Sin. 61, 1 (2012)

[14] X. Wang, R.Z. Chao, R.G. Guan, Y.D. Li, C.M. Liu, Acta Phys. Sin. 64, 1 (2015)
[15] R.G. Guan, Z.Y. Zhao, H.Q. Huang, Q.S. Zhang, C.M. Liu, Acta Metall. Sin. (Engl. Lett.) 25, 81 (2012)

[16] R.G. Guan, Z.Y. Zhao, R.Z. Chao, H.Q. Huang, C.M. Liu, Acta Metall. Sin. (Engl. Lett.) 25, 320 (2012)

[17] Y.S. Shen, B.W. Li, M.L. Wu, Basic Principles of Metallurgical Transmission, 1st edn. (Metallurgical Industry Press, Beijing, 2000), pp. 5-46

[18] G.J. Chen, Y.J. Zhang, Y.S. Yang, Chin. Phys. B 22(12), 1 (2013)

[19] J.C. Yu, L.Z. Xin, J. Eng. Thermophys. 26, 131 (2005)

[20] A.K. Dahle, L. Arnberg, Acta Mater. 45, 547 (1997)

[21] D.Y. Guo, Y.S. Yang, W.H. Tong, F.A. Hua, G.F. Cheng, Z.Q. $\mathrm{Hu}$, Acta Metall. Sin. (Engl. Lett.) 39, 914 (2003) 